\title{
A randomized comparison between three types of irrigating fluids during transurethral resection in benign prostatic hyperplasia
}

\author{
Ayman A Yousef*, Ghada A Suliman, Osama M Elashry, Mahmoud D Elsharaby and Abd El-naser K Elgamasy
}

\begin{abstract}
Background: Central nervous system changes, circulatory and electrolyte imbalances are the main complications of endoscopic transurethral resection of the prostate (TURP) which is known as transurethral resection (TUR) syndrome, which occurs as result of excessive absorption of irrigating fluid. We compare glycine $1.5 \%$ versus glucose $5 \%$ and normal saline $0.9 \%$ as irrigating solutions during TURP in patients with moderate to severe bladder outlet obstruction due to benign prostatic hyperplasia (BPH).
\end{abstract}

Methods: Three hundred sixty patients with symptomatic BPH were randomized into a prospective, controlled trial comparing the three irrigation modalities. One-hundred twenty patients used glycine $1.5 \%$ solution as irrigating fluid (glycine group), 120 patients used glucose 5\% solution (glucose group) and 120 patients used normal saline 0.9\% solution (saline group). Patient's demographics, operation time, hospital stay, postoperative amino acid glycine assay, postoperative serum cardiac troponin I and perioperative complications were noted.

Results: No difference was found between the groups in the immediate postoperative levels of hemoglobin and hematocrite. A high glycine level was associated with the TUR syndrome. Seventeen patients had TUR syndrome; all were in glycine group and they had the highest postoperative amino acid glycine levels. Slight increase in serum sodium (142.6 $\pm 12.6 \mathrm{mmol} / \mathrm{l})$ was detected in saline group. Transient Hyperglycemia $(170 \pm 35.9 \mathrm{mg} / \mathrm{dl})$ and hypokalemia (3.67 $\pm 0.92 \mathrm{mmol} / \mathrm{l})$ occurred in the immediate postoperative period in the glucose group.

Conclusion: Endoscopic TURP performed using either glucose $5 \%$ or saline $0.9 \%$ irrigating solution during and after surgery is associated with lower incidence of TUR syndrome, lower catheterization period, shorter hospital stay and no cardiac toxicity in comparison with glycine $1.5 \%$ solution.

Trial Registration: This clinical trail had been approved and registered in PACT Registry; with identification number for the registry is ATMR2010010001793131.

\section{Background}

Many endoscopic surgical procedures require the use of an irrigating fluid to dilate the operating field and to wash away debris and blood. A potential complication of such irrigation is a systemic absorption of the fluid to the extent that overt symptoms are produced [1]. The ideal irrigant for endoscopic resection would be a userfriendly, non-conductor medium that does not interfere with diathermia, has a high degree of translucency, has similar osmolarity to the serum and causes only minimal

\footnotetext{
* Correspondence: ayman.yousef@rocketmail.com

17 El-emam Moslem street, Tanta, Egypt

Full list of author information is available at the end of the article
}

side effects when absorbed [2]. There are several different irrigating fluids available commercially and it may be difficult to know which one to use. The choice tends to be governed largely by tradition, although the price and properties of the fluid (e.g. stickiness and transparency) also play a role. The pharmacological effects of the fluid become important whenever it is absorbed by the patient. Glycine is an endogenous amino acid without an allergic reaction potential. It is transparent and reasonably inexpensive. However, the solution is unphysiological because it lacks electrolyte and excessive absorption is a recognized complication [3]. Nausea, vomiting, confusion and arterial hypotension occur significantly more often when 
between 1.000 and $2.000 \mathrm{ml}$ of glycine solution are absorbed. Severe forms of TUR syndrome are more rare but they require treatment in the intensive care unite (ICU) at least over night. The incidence and severity of symptoms of TUR syndrome increase progressively as more glycine solution is absorbed during TURP and the severity of symptoms is markedly aggravated when more than 3,000 $\mathrm{ml}$ are absorbed [4]. Deaths have been reported in patients undergoing TURP. Laboratory studies in animals showed that glycine has direct and indirect cardiotoxic effects [5].

Unlike glycine, glucose is a physiological solution that is readily metabolized when absorbed in most patients [6]. The aim of this study is to compare perioperative morbidity, operation time, and length of hospital stay for glycine $1.5 \%$ versus glucose $5 \%$ and saline $0.9 \%$ as irrigating solutions during TURP in patients with moderate to severe bladder outlet obstruction due to benign prostatic hyperplasia (BPH).

\section{Methods}

After the study was approved by an Investigational Review Board of Faculty of Medicine, Tanta University, an informed consent was obtained from patients participating in the study. Randomization was performed by computer-generated random allocations sequence by simple randomization. A total of 360 patients undergoing TURP for BPH at Urology Department, Tanta University Hospitals were included in the study. Patients were divided into three groups according to the irrigating fluid used and randomly allocated to use either glycine 1.5\% solution (glycine group, $\mathrm{n}=120$ ), glucose $5 \%$ (glucose group, $\mathrm{n}=120$ ) or normal saline $0.9 \%$ solution (saline group, $\mathrm{n}=120$ ) as irrigating fluid during and immediately after TURP (Figure 1). TURP was performed using $24 \mathrm{Ch}$ continuous irrigating resectoscope (Storez, Tottling, Germany). Patients in saline group used bipolar loop (Storez, Tottling, Germany) as a working element for bipolar current, while the other two groups used 24Ch cutting loop and $24 \mathrm{Ch}$ roller loop as a working element for resectoscope for monopolar current (Storez, Tottling, Germany).

The operating room nurse assisting in the procedure randomized the patients and prepared the irrigating fluids appropriately, also enrolled the participants and assigned participants to their respective groups. All patients had been designed to receive spinal anesthesia in the form of $2.5 \mathrm{ml} 0.5 \%$ hyperbaric bupivacaine mixed with fentanyl $20 \mu \mathrm{g}$ intrathecally, commencement of surgery is allowed when adequate sensory block to $\mathrm{T} 10$ at the umbilical level was achieved. Surgical intervention was performed by surgeons of the same qualification and clinical experience.

Evaluation of the patients included complete medical history, ultrasound for abdomen and pelvis, routine labo- ratory investigations (complete blood count, blood urea nitrogen, blood sugar, serum sodium, potassium, prothrombin time, albumin) and prostatic specific antigen (PSA). Immediate preoperative as well as postoperative hemoglobin, hematocrite, serum sodium and potassium, blood urea, serum creatinine, random blood glucose, serum osmolarity, arterial blood gas, as well as serum troponin-I as a cardiac cell injury marker were measured. No patients had received colloid, plasma products, hypertonic saline, diuretic therapy or blood transfusion approximately 10 hours before surgery.

Exclusions criteria included patients with bleeding disorders or existing coagulopathy, diabetes mellitus or other metabolic acidosis and apparent cardiac disease with ECG evidence of ischemia, history of myocardial infarctions and congestive cardiac failure, renal insufficiency as well as any contraindication to spinal anesthesia. All patients were pre-loaded with $500 \mathrm{ml}$ ringer solution one hour before induction of spinal anesthesia. No patients received intravenous glucose or glucose saline before, during or immediately after surgical procedure. Central venous pressure catheter was inserted just before surgery to judge the status of the intravascular volume and trans-compartmental fluid shift.

Hemodynamic monitoring including: heart rate (HR), electrocardiogram (ECG), mean arterial blood pressure (MABP) and central venous pressure (CVP) were recorded. Hypotension, defined as $20 \%$ fall in blood pressure from pre-induction levels or a systolic blood pressure lower than $100 \mathrm{mmHg}$, was treated immediately by intravenous injecting of 5-10 mg ephedrine. The amount of irrigation fluids used in each patient is calculated depending upon gravimetric methods and the height of the irrigating fluid reservoir is fixed at $60 \mathrm{~cm}$ height from patients' bed.

TUR syndrome was defined as sodium of $125 \mathrm{mmol} / \mathrm{l}$ or less after TURP with 2 or more symptoms or signs of TUR syndrome such as nausea, vomiting, bradycardia, hypotension, chest pain, mental confusion, anxiety, parasthesia and visual disturbance [7]. Operative details including operation time, resected tissue weight, irrigating volume used, evidence of prostatic capsule perforation, catheterization time, duration of hospital stay as well as any perioperative complication were recorded. The medical and nursing stuff involved in patients care, monitoring in the post-operative period and assessment of the complications and the incidence and the severity of TUR syndrome were completely blinded to the patient's group assignment and the type irrigating fluid used.

\section{Glycine assay using thin layer chromatography}

Thin layer chromatography is semi-quantitative method for amino acid glycine separation and assay. The principle of separation depends on differences in both the degree 


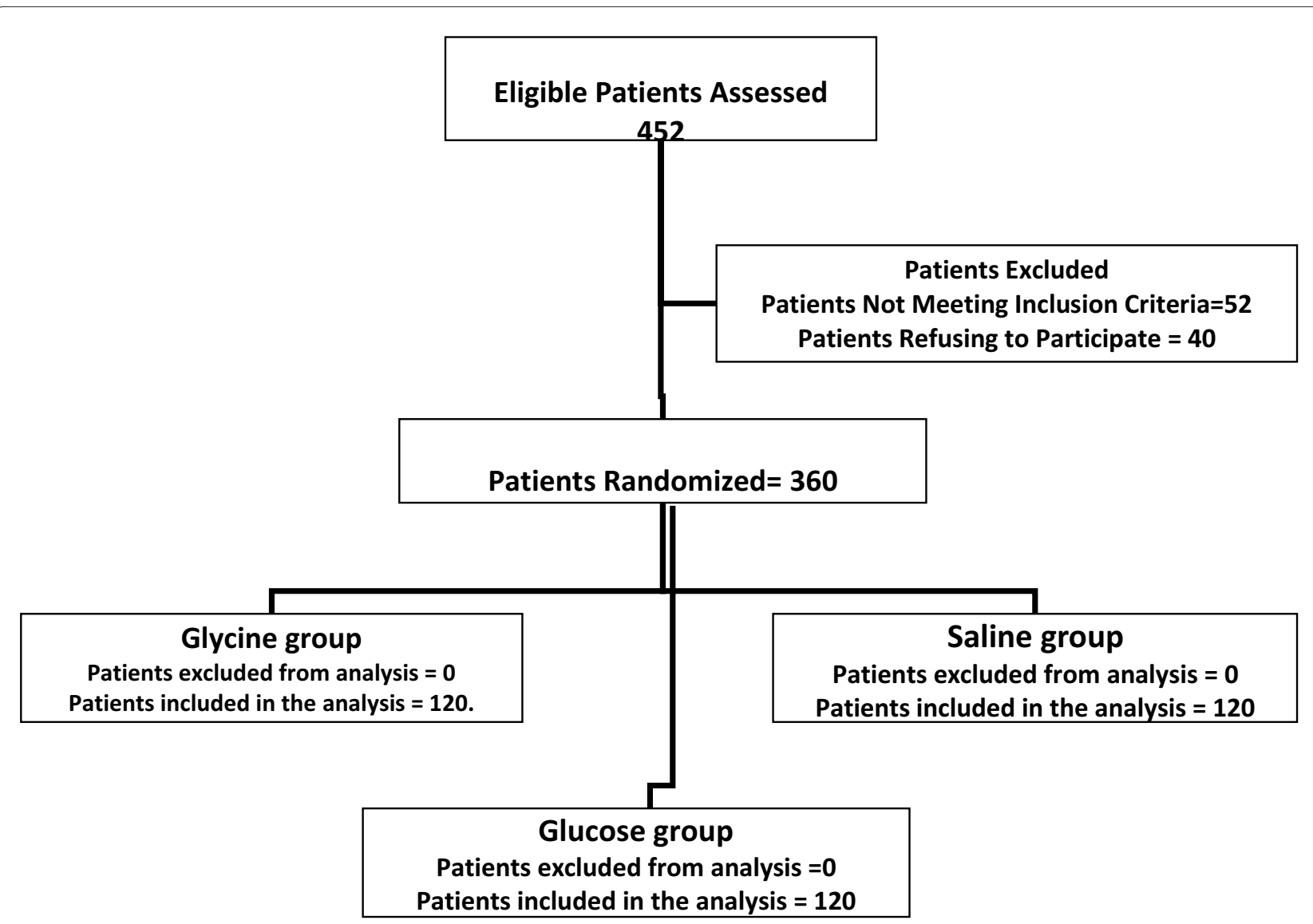

Figure 1 Schematic presentation of patient flow through out trail period

of adsorption by the adsorbent and solubility in the solvent used for separation, using a uniform thin layer of adsorbent on a supporting glass plate then plates are dried in an oven at $100-120^{\circ} \mathrm{C}[8]$.

\section{Troponin I assay}

It is a qualitative membrane fixed immunoassay for the detection of calcium troponin I (cTnI) in whole blood, serum or plasma. The membrane is pre-coated with capture reagent in the test line regions. During the test, the serum or plasma sample react with the particle coated anti-c TnI antibodies. The mixture migrates upward on the membrane chromatographically by capillary action to react with capture reagent on the membrane and generate a colored line according to the manufacturer guide (ACON Laboratories, Inc. San Diego, USA). The presence of this colored line in the test line region indicates a positive result; while its absence indicates negative results [9].

\section{Statistics}

Continuous parametric data variables are reported as mean \pm SD and were analyzed with analysis of variance, while categorical and non-parametric variables were ana- lyzed using $\mathrm{x}_{2}$ tests. A $\mathrm{p}$ value $<0.05$ was considered significant. Based on a previous study of fluid irrigation of TUR syndrome, considering a 0.052 -sided significance level, a power of $80 \%$, and allocation ratio of $1: 1$, and allowing for $10 \%$ attrition/non-compliance rate, a group size contains $100-120$ patients in each group were estimated to be sufficient $[2,6]$.

This clinical trail had been approved and registered in PACT Registry; with identification number for the registry is ATMR2010010001793131.

\section{Results}

The age of the patients ranged from 53 to 70 years old $(60.7 \pm 5.1)$ in the glycine group and 55-71 years old (60.9 \pm 4.9 ) in the glucose group while it was 50-67 years old $(62 \pm 6.5)$ in the saline group. The operation time range was $45-70 \mathrm{~min}$ in glycine group $(57.1 \pm 8.2)$ and it was 40 75 min $(58.3 \pm 10.8)$ minutes in glucose group while it was $55-80 \mathrm{~min}(62.5 \pm 11.2)$ in saline group. The mean amount of prostatic tissue resected was $89.16 \mathrm{gm} \pm$ 18.3 (range70 to 125 ) gm in the glycine group and $91.9 \mathrm{gm}$ \pm 16 (range 75 to 120 ) gm in the glucose group while it was 82.5 gm \pm 15.5 in saline group (range70-110). Only12 
resections in glycine group and 8 in glucose group the amount of tissue resected exceed or equal to $120 \mathrm{gm}$. The indwelling catheter was removed after $2.4 \pm 0.71$ days (range 2 to 4 ) in the glycine group and after1.67 \pm 0.45 days (range 1 to 2 ) in the glucose group while after $1.54 \pm$ 0.34 (range1 to2) in saline group. Hospital stay was $3.31 \pm$ 0.63 days (range 3 to 5 ) in glycine group and $2.29 \pm 0.46$ days (range 2 to 3 ) in glucose group, while it was $2.19 \pm$ 0.38 days in saline group (range 2 to 3 ). (Table 1 )

The hemodynamic changes regarding heart rate (HR), mean arterial blood pressure (MABP) and central venous pressure (CVP) were compared between groups. There was no significant difference in the preoperative mean value of HR (beat $/ \mathrm{min}$ ) between the studied groups. Ten minutes after induction of anesthesia, there was a significant decrease in the mean value of HR $(57.5 \pm 12.6$ beat/ $\min \& 56.4 \pm 13.5$ beat $/ \mathrm{min} \& 54.6 \pm 11.9$ beat $/ \mathrm{min}$ ) in the glycine, glucose and saline groups respectively. Then, no significant change was found through out the intraoperative and immediate postoperative period in the studied groups.

There was no significant difference in the preoperative average MABP ( $\mathrm{mmHg}$ ) between the studied groups. Ten minutes after induction of anesthesia, there was a significant decrease in the average MABP $(71.6 \pm 19.6 \mathrm{mmHg} \&$ $73.4 \pm 18.5 \mathrm{mmHg} \& 72.5 \pm 18.8 \mathrm{mmHg}$ ) in the glycine, glucose and saline groups respectively. Then, No significant change in the average MABP was found in the studied groups through out the study period.

The mean value of CVP in the studied groups was similar in the preoperative period in the studied groups. Then, significant decrease in the mean value $(3.26 \pm 0.95$ $\mathrm{cm} / \mathrm{H}_{2} \mathrm{O} \& 3.1 \pm 0.85 \mathrm{~cm} / \mathrm{H}_{2} \mathrm{O} \& 3.3 \pm 0.7 \mathrm{~cm} / \mathrm{H}_{2} \mathrm{O}$ ) occurred $10 \mathrm{~min}$ after induction of anesthesia in the glycine, glucose and saline groups respectively. After 20 and $30 \mathrm{~min}$, no significant change was found in the studied groups, however, significant increase in the mean value of
CVP was measured at 60 min to mean value of $(8.5 \pm 2.4$ $\left.\mathrm{cm} / \mathrm{H}_{2} \mathrm{O} \& 8.4 \pm 2.12 \mathrm{~cm} / \mathrm{H}_{2} \mathrm{O} \& 9.2 \pm 2.6 \mathrm{~cm} / \mathrm{H}_{2} \mathrm{O}\right)$ and $\left(9.5 \pm 2.54 \& 9.4 \pm 2.15 \mathrm{~cm} / \mathrm{H}_{2} \mathrm{O} \& 10.2 \pm 2.95 \mathrm{~cm} / \mathrm{H}_{2} \mathrm{O}\right)$ in the postoperative period in the studied groups respectively. (Table 2)

There was no significant difference in the mean value between the studied groups regarding the preoperative hemoglobin, serum sodium, serum potassium and random blood sugar. Insignificant decrease in the postoperative serum sodium was observed in glycine and glucose groups, while insignificant increase was observed in saline group $(142.6 \pm 12.6 \mathrm{mmol} / \mathrm{l})$. Insignificant reduction in serum potassium in glycine and saline group was observed, but more pronounced decrease in glucose group $(3.67 \pm 0.92 \mathrm{mmol} / \mathrm{l})$ was measured postoperatively. There was a significant elevation in the postoperative mean value of blood sugar level in the glucose group $(170.2 \pm 35.9 \mathrm{mg} / \mathrm{dl})$ which returned back to normal level 6 hours postoperatively. (Table 3 )

Two Patients in glycine and another 2 patients in glucose group needed blood transfusion, who experienced a decrease in hemoglobin concentration to less than $9 \mathrm{~g} / \mathrm{dl}$. TUR syndrome developed in 17 patients in the glycine group but non in neither glucose nor saline groups. Elevated glycine levels was observed in 36 patients in glycine group of whom the highest 17 values suffered TUR syndrome. Six patients in the glycine group developed ischemic ECG changes. Three patients in glycine group developed elevated troponin I. These patients admitted to post anesthesia care unite for proper treatment. (Table 4)

\section{Discussion}

This randomized single blinded trail was performed in patients with prostatic hyperplasia admitted for endoscopic resection of the prostate using three different types of irrigating fluids during resection, demonstrated

Table 1: Patients characteristic of studied groups. (Means \pm SD)

\begin{tabular}{lll}
\hline & $\begin{array}{l}\text { Glycine group } \\
(\mathbf{n}=\mathbf{1 2 0})\end{array}$ & $\begin{array}{l}\text { Glucose group } \\
(\mathbf{n}=\mathbf{1 2 0})\end{array}$ \\
\hline Age (years) & $60.7 \pm 5.1$ & $60.9 \pm 4.9$ \\
\hline Operative time (min) & $57.1 \pm 8.2$ & $58.3 \pm 10.8$ \\
\hline Resection wt (gm) & $89.16 \pm 18.3$ & $91.94 \pm 16$ \\
\hline Catheterization time (days) & $2.4 \pm 0.71$ & \\
\hline Hospital stay (days) & & $1.67 \pm 0.45$ \\
\hline Analysis of variance & & \\
\hline
\end{tabular}

Analysis of variance tests were used. 
Table 2: Homodynamic changes in the studied groups. (Means)

\begin{tabular}{|c|c|c|c|c|c|c|}
\hline & $\begin{array}{c}\text { Pre-op Gly/ } \\
\text { Glu/Sal }\end{array}$ & $\begin{array}{c}10 \mathrm{~min} \text { Gly/Glu/ } \\
\text { Sal }\end{array}$ & $\begin{array}{c}20 \text { min Gly/ } \\
\text { Glu/Sal }\end{array}$ & $\begin{array}{c}30 \text { min Gly/ } \\
\text { Glu/Sal }\end{array}$ & $\begin{array}{c}60 \mathrm{~min} \text { Gly/Glu/ } \\
\text { Sal }\end{array}$ & $\begin{array}{c}\text { post-op Gly/ } \\
\text { Glu/Sal }\end{array}$ \\
\hline HR & $62.4 / 64.2 / 63.6$ & $57.5^{*} / 56.4^{*} / 54.6^{*}$ & $63.2 / 63 / 62.6$ & $64.1 / 64 / 63.6$ & $60.26 / 61.5 / 64.5$ & $60.9 / 61.8 / 65.2$ \\
\hline MABP & $90.3 / 91.5 / 92.6$ & $71.6^{*} / 73.4^{*} / 72.5^{*}$ & 87.9/88.8/94 & $89.2 / 91.2 / 96.4$ & 91.6/95.8/98.2 & $93.2 / 96.1 / 99.4$ \\
\hline CVP & $5.15 / 5.3 / 5.9$ & $3.26^{*} / 3.1^{*} / 3.3^{*}$ & $5.6 / 5.09 / 5.2$ & $6.66 / 6.4 / 5.9$ & $8.5^{*} / 8.4^{*} / 9.2^{*}$ & $9.5^{*} / 9.4^{*} / 10.2^{*}$ \\
\hline
\end{tabular}

high incidence of TUR syndrome in patients used glycine $1.5 \%$ solution, while non in neither glucose nor saline groups developed TUR syndrome. Elevated glycine levels was observed in patients in glycine group of whom the highest values suffered TUR syndrome and was associated with ischemic ECG changes and elevated troponin I in these patients.

The use of an irrigating fluid during many endoscopic surgical procedures is mandatory to dilate the operating field and to wash away debris and blood. The systemic absorption of such an irrigating fluid may be associated with serious complications. Large-scale fluid absorption is rare but leads to symptoms severe enough to require intensive care. Patho-physiological mechanisms consist of pharmacological effects of irrigant solutes, the volume effect of irrigant water, dilutional hyponatraemia and brain edema [1].

Glycine solution is the most commonly used irrigant in TURP. Many studies performed on human denoting that glycine absorption causes echocardiogram changes and it is associated with increased troponin I [6]. Another experimental studies showed that glycine has a cardiotoxic properties and fluid absorption during TURP has devitalizing effect on the heart [10]. High glycine levels are suspected of causing cerebral edema [11], visual disturbances and even transient blindness [12,13].

Hyper-ammonaemic encephalopathy may develop as ammonia is an intermediate product in glycine metabolism [14]. Another disorder of glycine metabolism characterized by episodes of ketosis and metabolic acidosis that may proceed to coma had been reported [15]. Potentially safer alternatives to glycine irrigation are normal saline $0.9 \%$ and glucose $5 \%$ to be used as irrigating fluid during TURP. Normal saline is the ideal irrigation fluid for TURP; however its electrical conducting properties prohibit its use with conventional monpolar TURP system in the past. The advance of using bipolar resectoscope that allows resection using normal saline allows us to use it safely with no risks of precipitating hyponatreamia which is the main pathology in TUR syndrome. However, it is rapid infusion of normal saline $0.09 \%$ that can cause hypercholeramic metabolic acidosis $[7,11]$.

Glucose $5 \%$ is relatively more physiological than glycine because it can be given intravenously and with lower incidence of complication. A solution of glucose $5 \%$ is metabolized throughout the body, it requires $13 \mathrm{~L}$ to be given/

Table 3: Chemical and hematological values of studied groups in the immediate postoperative period. (Means \pm SD)

\begin{tabular}{|c|c|c|c|}
\hline & $\begin{array}{l}\text { Glycine group } \\
(n=120)\end{array}$ & $\begin{array}{l}\text { Glucose group } \\
(n=120)\end{array}$ & $\begin{array}{l}\text { Saline group } \\
(n=120)\end{array}$ \\
\hline Hemoglobin (gm/dl) & $11.1 \pm 1$ & $10.9 \pm 9$ & $11.4 \pm 1.2$ \\
\hline Sodium (mmol/l) & $134.7 \pm 13.4$ & $135.5 \pm 12.9$ & $142.6 \pm 12.6$ \\
\hline Potassium (mmol/l) & $3.87 \pm 1.17$ & $3.67 \pm 0.92$ & $4.16 \pm 1.32$ \\
\hline Random blood sugar (mg/dl) & $113.5 \pm 25.5$ & $170.2^{*} \pm 35.9$ & $116.8 \pm 28.4$ \\
\hline
\end{tabular}

*Statistically significance $(p<0.05 \%)$.

Analysis of variance tests were used. 
Table 4: Peri-operative complications in the studied groups.

\begin{tabular}{lccc}
\hline & $\begin{array}{c}\text { Glycine group } \\
(\mathbf{n}=\mathbf{1 2 0})\end{array}$ & $\begin{array}{c}\text { Glucose group } \\
(\mathbf{n}=\mathbf{1 2 0})\end{array}$ & $\begin{array}{c}\text { Saline group } \\
(\mathbf{n}=\mathbf{1 2 0})\end{array}$ \\
\hline TUR syndrome & $17^{*}$ & 0 & 0 \\
\hline ECG changes & 6 & 0 & 0 \\
\hline Elevated glycine & $36^{*}$ & 0 & 0 \\
\hline Elevated tropnin-I & 3 & 0 & 1 \\
\hline Clot retention & 0 & 0 & 0 \\
\hline $\begin{array}{l}\text { Blood transfusion } \\
\text { Urinary retention }\end{array}$ & 2 & 2 & 0 \\
\hline $\begin{array}{l}\text { Statistically significance }(\mathrm{p}<0.05 \%) . \\
\text { X test was used. } \\
\text { TUR syndrome: trans-urethral resection syndrome. }\end{array}$ & 0 & \\
\hline
\end{tabular}

absorbed intravenously to expand the intravascular compartment by $1 \mathrm{~L}$ [2].

Normal serum osmolality is $\approx 290 \mathrm{mOsm} / \mathrm{L}$. The osmolality of normal saline $0.9 \%$ is about $300 \mathrm{mOsm} / \mathrm{L}$, and that of glucose $5 \%$ is $285 \mathrm{mOsm} / \mathrm{L}$, as opposed to the osmolality of glycine $1.5 \%$, which is $190 \mathrm{mOsm} / \mathrm{L}$. This higher osmolality provided by both normal saline $0.9 \%$ and glucose $5 \%$ solution may be beneficial in reducing the possible side effects of cerebral edema.

Issa et al., [11] in a case study concluded that bipolar saline is a safe and eliminates the risk of TUR syndrome in high-risk patients with large prostates. Michielsen et al., [7] concluded in his study that a bipolar transurethral resection in saline system is as efficacious as monopolar transurethral prostate resection but it is safer than the latter because of the lesser changes in post-operative sodium, and the smaller risk of transurethral resection syndrome.

Two studies done by Collins et al, [2,6] the first study concluded that an increase in serum glycine was associated with TUR syndrome; there were large variations in the amounts of glycine absorbed, reaching levels many times the upper limit of normal, and although there was immediate postoperative hyperglycemia in patients used glucose $5 \%$ as irrigation fluid during TURP, it was not associated with either ECG changes nor elevated serum troponin I. In the second study, glycine was reportedly toxic, producing ECG changes and increase in the serum troponin I. Unrecognized blood loss or glycine absorption may explain the increase in morbidity and mortality reported in patients who undergo TURP.

\section{Conclusion}

Endoscopic transurethral of the prostate performed using either bipolar normal saline $0.9 \%$ resection, or monoplar glucose $5 \%$ resection as irrigating solution during and after surgery, when compared with monoplar glycine $1.5 \%$ resection, are associated with lower perioperative morbidity including TUR syndrome, lower catheterization period and shorter hospital stay. Except for the transient postoperative hyperglycemia, in glucose group, both systems are nearly equivalent.

\section{Authors' Details}

Ayman A Yousef.

Lecturer of Anesthesiology, Department of Anesthesia, Tanta University Hospitals, El-Geish street, Tanta, 31527, Egypt.

\section{Ghada A Suliman.}

Lecturer of Clinical Pathology, Department of Clinical Pathology, Tanta University Hospitals, El-Geish street, Tanta, 31527, Egypt.

Osama M Elashry.

Assistant professor of Urology, Department of Urology, Tanta University Hospitals, El-Geish street, Tanta, 31527, Egypt.

Mahmoud D Elsharaby.

Professor of Urology, Department of Urology, Tanta University Hospitals, El-Geish street, Tanta, 31527, Egypt.

Abd El-naser K Elgamasy. 
Professor of Urology, Department of Urology, Tanta University Hospitals, El-Geish street, Tanta, 31527, Egypt.

\section{Abbreviations}

TURP: Transurethral resection of the prostate; CVP: Central venous pressure; TUR Syndrome: Transurethral resection syndrome; HR: Heart rate; BPH: Benign prostatic hyperplasia; PSA: Prostatic specific antigen; C Tn I: Calcium troponin I; ECG: Electrocardiogram; MABP: Mean arterial blood pressure.

\section{Competing interests}

The authors declare that they have no competing interests.

\section{Authors' contributions}

AAY performed the anesthetic management, prepared the manuscript, and patients follow up. O M Elashry, M D Elsharaby and A K Elgamasy performed the surgical intervention and patients follow up. GAS prepared the lab results and assessed in manuscript preparation. All authors read and approved the final manuscript.

\section{Acknowledgements}

The authors would like to thank the nursing staff of Urology Department, Tanta University for their effort during this study.

\section{Author Details}

17 El-emam Moslem street, Tanta, Egypt

Received: 4 December 2009 Accepted: 28 May 2010

Published: 28 May 2010

\section{References}

1. Hahn RG: Fluid absorption in endoscopic surgery. Br J Anesthesia 2006, 96:8-20.

2. Collins JW, Macdermott S, Bradbrook RA, Keeley FX Jr, Timoney AG: A comparison of the effect of $1.5 \%$ glycine and $5 \%$ glucose irrigants on plasma serum physiology and the incidence of transurethral resection syndrome during prostate resection. Br J Urol 2005, 96:368-72.

3. Hahn RG: Irrigating fluids in endoscopic surgery. Br J Urol 1997, 79:669-80.

4. Olsson J, Nilsson A, Hahn RG: Symptoms of the transurethral resection syndrome using glycine as the irrigant. The J Urol 1995, 154:123-8.

5. Hahn RG, Olssen J: Ethanol monitoring of the transurethral resection syndrome. J Clin Anesth 1996, 8:652-5.

6. Collins JW, Macdermott S, Brad brook RA, Drake B, Keeley FX, Timoney AG: The effects of the choice of irrigating fluid on cardiac stress during Transurethral resection of the prostate: A comparison between 1.5\% Glycine and 5\%glucose. J Urol 2007, 177:1369-73.

7. Michielsen DP, Debacker T, De Boe V, Van Lersberghe C, Kaufman L, Braeckman JG, Amy JJ, Keuppens Fl: Bipolar transurethral resection in saline-an alternative surgical treatment for bladder outlet obstruction? J Urol 2007, 178:2035-9.

8. Kazmierczak D, Ciesielski W, Zakrzewski R, Zuber M: Application of iodine-azide reaction for detection of amino acids in thin-layer chromatography. J Chromatography A 2004, 1059:171-4

9. Apple FS, Falahati A, Paulsen PR, Miller EA, Sharkey SW: Improved detection of minor ischemia myocardial injury with measurement of serum cardiac troponin I. Clin Chem 1997, 43(11):2047-51.

10. Zhang W, Andersson BS, Hahn RG: Effect of irrigating fluids and prostatic tissue extracts on isolated cardiomyocytes. Urology 1995, 46:821-4.

11. Issa MM, Young MR, Bullock AR, Bouetand R, Petrous JA: Dilutional Hyponatraemia of TURP syndrome: A historical event in the $21^{\text {st }}$ century. Urology 2004, 64:298-301.

12. Hahn RG: Hallucination and visual disturbances in transurethral prostatic resection. Intensive Care Med 1988, 14:668-71.

13. Wang JM, Creel DJ, Wong KC: Transurethral resection of the prostate, Serum Glycine levels, and ocular evoked potentials. Anesthesiology 1989, 70:36-41.

14. Hahn RG: Serum amino acid pattern and toxicity symptoms following the absorption of irrigant containing glycine in transurethral prostatic surgery. Acta Anaesthesiol Scand 1988, 32:493-501.
15. Flusser H, Korman SH, Sato K, Matsubara Y, Galil A, Kure S: Mild glycine encephalopathy in a large kindred due to a silent exonic GLDC splice mutation. Neurology 2005, 64:1426-30

\section{Pre-publication history}

The pre-publication history for this paper can be accessed here: http://www.biomedcentral.com/1471-2253/10/7/prepub

doi: 10.1186/1471-2253-10-7

Cite this article as: Yousef et al., A randomized comparison between three types of irrigating fluids during transurethral resection in benign prostatic hyperplasia BMC Anesthesiology 2010, 10:7

\section{Submit your next manuscript to BioMed Central} and take full advantage of:

- Convenient online submission

- Thorough peer review

- No space constraints or color figure charges

- Immediate publication on acceptance

- Inclusion in PubMed, CAS, Scopus and Google Scholar

- Research which is freely available for redistribution
C BioMed Central 